Medicine in the Elderly

\title{
The use of digoxin in 55 residential homes for elderly people
}

\author{
P.B. Weedle, J.W. Poston and P.A. Parish \\ Medicines Research Unit, Division of Clinical Pharmacy, Welsh School of Pharmacy, Redwood Building, \\ UWIST, Cathays Park, Cardiff CF1 3XF, UK.
}

\begin{abstract}
Summary: Data relating to the use of digoxin from a descriptive epidemiological study of drug use in residential homes for elderly people were analysed. Of the 1,888 residents in the study homes, 212 were receiving cardiac glycosides. The ratio of females to males who received cardiac glycosides was 2.8:1; however, this was not statistically significant as it reflected the overall population. The median age of recipients of cardiac glycosides was $\mathbf{8 5 . 2}$ years and they were significantly older than non-recipients $(P<0.001)$. The cardiac glycosides were almost exclusively prescribed as digoxin, the median dose was $125 \mu \mathrm{g}$ with a range of 62.5 to $250 \mu \mathrm{g}$, and the median duration of treatment was 2.3 years, range $<0.1$ to 10.1 years. Digoxin was involved in a total of 152 potential drug interactions, 12 of which were potentially highly significant clinically.
\end{abstract}

\section{Introduction}

Individuals 60 years of age or older are at increased risk from drug treatment due to a reduced ability to handle drugs and increased sensitivity to pharmacological effects. ${ }^{1-3}$ Adverse drug reactions have been reported as less than $3 \%$ in persons aged 20 to 29 years but as high as $21 \%$ in those over 70 years of age. ${ }^{4,5}$

Cardiac glycosides are among the most commonly used drugs in elderly patients and diminished excretion in the elderly predisposes the patient to serious adverse effects. The incidence of digoxin toxicity is estimated at between 23 to $30 \%{ }^{6-10}$ The higher incidence of toxicity associated with digoxin in older patients is more closely related to reduced renal function, accompanied by higher and more prolonged serum concentrations, than to an increased sensitivity of the heart to the action of the drug. ${ }^{11}$

It has been suggested that the use of maintenance digoxin is often unnecessary. ${ }^{12,13}$ In several studies digoxin therapy was withdrawn from elderly patients without detriment ${ }^{14,15}$ and Dall ${ }^{16}$ showed that of a group of patients on long-term digoxin therapy, $75 \%$ suffered no harm through digoxin therapy being stopped.

Correspondence: J.W. Poston, B.Pharm., Ph.D., M.P.S. Accepted: 4 November 1987
When continuing digoxin therapy is indicated, it should be given in smaller doses in older patients, ${ }^{17}$ yet a study, designed specifically to assess the use of digoxin in a group of 42 elderly patients, revealed that only 1 in 3 were receiving an appropriate dose. ${ }^{18}$

While the majority of the elderly live in the community in their own homes and only a small proportion (approximately 5\%) live in residential accommodation, the latter are a unique population in that they are a 'captive' group in which compliance with drug treatment can be ensured by staff in the home. These elderly people appear to have minimal contact with their general medical practitioner and pharmacist, since surrogates order, collect and administer their medicines. There is, however, a lack of detailed studies of drug use by elderly people in residential homes. ${ }^{19-23}$

In the present study, which was designed to provide information on drug usage in the elderly, an assessment was made of the extent and appropriateness of the use of cardiac glycoside medicines by elderly people in residential homes.

\section{Methods}

Fifty-five residential homes in two local authorities were visited in 1984 over a 6-month period and

(C) The Fellowship of Postgraduate Medicine, 1988 
data were obtained from the officers-in-charge, the drug administration records and the stock of medicines held in the home. Officers-in-charge were also interviewed about the supply, recording, storage and use of medicines within the residential home. The medicinal treatments for each resident were listed on a form which was sent to the residents' general medical practitioners who were asked to add information on diagnoses and to indicate when treatments were started. The data were analysed using the Statistical Package for the Social Sciences. ${ }^{24}$ The statistical tests used were the Chi-squared test to analyse nominal and ordinal data for independent samples and the MannWhitney $U$ test for ordinal and interval data for two independent samples. The tests were applied according to the established procedures and assumptions. ${ }^{25}$

\section{Results}

Of the total of 1,888 residents in the study homes, $1,617(85.6 \%)$ were receiving medicines (defined as a single proprietary or generic preparation prescribed for an individual) daily. These residents received a total of 5,535 medicines per day, a median of three medicines per patient per day and a range of one to 13 medicines per day. A total of 615 different medicinal preparations were being used. Not all residents were excluded at this stage. Of the remaining 1,605 residents who received medicines, $212(13.2 \%)$ were receiving cardiac glycosides. These 212 residents received a total of 1,930 medicines, $23 \%$ of which were cardiac glycosides.

The results for the age, sex and duration of stay for recipients of cardiac glycosides are shown in Table I. The ratio of females to males was 2.8:1.
There was no significant difference between the proportion of males to females who received cardiac glycosides compared with the overall proportion of residents who received medicines.

The recipients of cardiac glycosides were significantly older than non-recipients $(P<0.001)$. When analysed by sex, both female and male recipients were significantly older than female and male nonrecipients (females: $P<0.01$; males: $P<0.03$ ). Male recipients were significantly younger than female recipients $(P<0.002)$ and similarly for non-recipients $(P<0.001)$.

Those residents who received cardiac glycosides did not have a significantly shorter duration of stay than those who did not receive cardiac glycosides $(P<0.1)$. There was no significant difference in the duration of stay for recipients between the sexes $(P>0.07)$, however there was a difference between the sexes for non-recipients $(P<0.02)$ with females staying longer.

All but one of the 212 residents took digoxin (the other one took lanatoside C) prescribed as Lanoxin in 78 cases $(37 \%)$, the others as generic digoxin. The median dose was $125 \mu \mathrm{g}$ with a range of $62.5 \mu \mathrm{g}$ to $250 \mu \mathrm{g}$. The most frequent time of dosage was 'daily' which was ordered on $103(48.8 \%)$ prescriptions followed by 'in the morning' which was ordered on $79(37.4 \%)$ prescriptions. A diagnosis was obtained for $79(37.4 \%)$ patients receiving digoxin. General medical practitioners attending homes where they were responsible for a small number of patients provided less information than those who were responsible for a large number of patients. Whether or not this reflects a completeness of record keeping or simply reluctance to respond is difficult to say. Of the diagnoses provided, 43 indicated that digoxin was used for congestive heart failure, 15 for atrial fibrillation, 8 for left heart failure, 5 for paroxysmal tachycardia,

Table I Age, sex and duration of stay for recipients and non-recipients of digoxin

\begin{tabular}{|c|c|c|c|c|c|c|}
\hline \multirow[b]{2}{*}{ Residents } & \multicolumn{2}{|c|}{ Sex } & \multicolumn{2}{|c|}{$\begin{array}{c}\text { Age } \\
\text { (years) }\end{array}$} & \multicolumn{2}{|c|}{$\begin{array}{c}\text { Duration of stay } \\
\text { (years) }\end{array}$} \\
\hline & $n$ & $\%$ & Median & Range & Median & Range \\
\hline \multicolumn{7}{|l|}{ Recipients } \\
\hline Male & 55 & 25.9 & 82.8 & 64.4-93.6 & 2.0 & $<0.1-7.8$ \\
\hline Female & 157 & 74.1 & 85.7 & $65.0-100.3$ & 2.4 & $<0.1-55.4$ \\
\hline Total & 212 & 100.0 & 85.2 & $64.6-100.3$ & 2.3 & $<0.1-55.4$ \\
\hline \multicolumn{7}{|l|}{ Non-recipients } \\
\hline Male & 383 & 27.5 & 79.9 & $60.4-102.1$ & 2.2 & $<0.1-20.0$ \\
\hline Female & 1010 & 72.5 & 84.3 & $60.1-109.2$ & 2.6 & $<0.1-81.0$ \\
\hline Total & 1393 & 100.0 & 83.3 & $60.1-109.2$ & 2.6 & $<0.1-81.0$ \\
\hline
\end{tabular}


4 for cardiac arrhythmias, 2 for heart failure, one for pulmonary heart failure and one for oedema. Duration of treatment was obtained for $68(32.2 \%)$ patients on digoxin (median $=2.3$ years, range $<0.1$ to 10.1 years).

The retrospective analysis of data indicates that digoxin was involved in 152 drug interactions (Table II). These were assessed for clinical significance. ${ }^{26}$ Twelve of these may have been highly clinically significant. However the retrospective nature of the study meant that this could not be confirmed clinically. Residents on digoxin took a relatively large number of other medicines, so this high incidence of clinically significant drug interactions is not surprising and highlights the need for careful review of the use of digoxin and concurrent medication in the elderly.

\section{Discussion}

In the present investigation 1,502 medicines acting on the cardiovascular system (representing $27.1 \%$ of all medicines used) were received by 933 residents, nearly $50 \%$ of the entire population studied. This figure is in close agreement with Allwood et al. ${ }^{27}$ who reported that $25.3 \%$ of medicines for the elderly were cardiovascular medicines and Vener et al. ${ }^{28}$ who reported $22.8 \%$. Diuretics were the most frequently used cardiovascular medicine $(59.5 \%)$ followed by cardiac glycosides $(14.1 \%)$, vasodilators $(8.2 \%)$, betablockers $(2.7 \%)$ and antihypertensives (others) $(1.7 \%)$.

Probably more has been written about the use of digoxin in the elderly than almost any other single drug. Yet despite the amount of available literature there is still some controversy about whether maintenance digoxin therapy should be used, in what dose and for what duration.

For many years digoxin was considered the most appropriate treatment for congestive heart failure; however, this view has been challenged with diuretics being promoted as the treatment of choice for mild to moderate cardiac failure. ${ }^{29}$ The use of maintenance digoxin for cardiac failure in sinus rhythm is subject to debate. Studies have shown that digoxin can be discontinued in $75 \%^{16}$ to $86 \%$ of patients, ${ }^{30}$ the commonest cause of lack of success being atrial fibrillation. In the present study over $50 \%$ of available diagnoses indicated that digoxin was used for congestive heart failure and approximately $20 \%$ for atrial fibrillation.

Ewy et al. ${ }^{31}$ have demonstrated that within 24 hours after intravenous administration, serum digoxin levels were nearly twice as high in elderly
Table II Drugs interacting with digoxin

\begin{tabular}{|c|c|c|}
\hline Drug interacting & $\begin{array}{c}\text { Clinical } \\
\text { significance }\end{array}$ & Number \\
\hline
\end{tabular}

1. Cardiac arrhythmias may develop

Bendrofluazide

Frusemide

Indapamide

$\begin{array}{r}6 \\ 52 \\ 1 \\ \hline 59\end{array}$

2. Increases serum levels

Fenoprofen

Ibuprofen

Indomethacin

Naproxen

Nifedipine

Oxytetracycline

Piroxicam

Spironolactone

Tetracycline

Verapamil

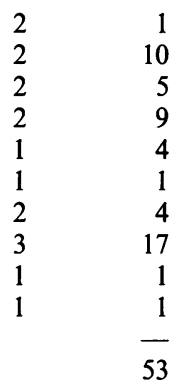

\section{Decreases therapeutic efficacy}

Thyroxine

2. Increases the half-life and decreases urinary excretion

Chlordiazepoxide

Diazepam

Flurazepam

Lorazepam

Oxazepam

5. Significantly decreases absorption Aluminium hydroxide

Magnesium hydroxide

\section{Significantly increases absorption} Benzhexol

Procyclidine

$1 \quad \begin{array}{r}2 \\ 2 \\ -\end{array}$

\section{Increase plasma concentration, reduce volume of distribution, increase half-life \\ Quinine}

2
6
1
2
1
12
3
5
8
2
2
4
1
1

8. Reduce serum levels

Sulphasalazine

2

TOTAL

Code for clinical significance: 1 - highly clinically significant; 2 - moderately clinically significant; 3 - minimally clinically significant. 
patients as in younger subjects given the same dose. Similarly another study ${ }^{32}$ found that the volume of distribution of digoxin is $40 \%$ lower in older than in younger patients. These findings indicate that lower doses than the standard adult dose of digoxin are appropriate for the elderly. The usual maintenance dose of digoxin in very old patients should be $125 \mu \mathrm{g}$ daily and toxicity is common in those given $250 \mu \mathrm{g}$ daily $\left(\mathrm{BNF}^{33}\right)$. However in the present study $44(21 \%)$ patients were receiving more than $125 \mu \mathrm{g}$ daily and $40(19 \%)$ were receiving $250 \mu$ g or more daily.

In the present study digoxin was involved in 152 potential drug-drug interactions which represented nearly $30 \%$ of all 509 possible potential drug-drug interactions. Digoxin was always the drug affected, the majority of the interactions increasing the serum levels of digoxin leading to the possibility of digoxin toxicity. This level of potential drug-drug interactions involving digoxin is a cause for concern given that 12 of the interactions were deemed to be potentially highly clinically significant.

Because oedema is usually associated with congestive cardiac failure, digoxin is frequently pre-

\section{References}

1. Triggs, E.J., Nation, R.L., Long, A. \& Ashley, J.J. Pharmacokinetics in the elderly. Eur $J$ Clin Pharmacol 1975, 8: 55-62.

2. Crooks, J., O'Malley, K. \& Stevenson, I.H. Pharmacokinetics in the elderly. Clin Pharmacokinet 1976, 1: 280-296.

3. Bender, A.D. Pharmacodynamic principles of drug therapy in the aged. J. Am Geriatr Soc 1974, 22: 296303.

4. Hurwitz, N. \& Wade, O.L. Intensive hospital monitoring of adverse reactions to drugs. $\mathrm{Br}$ Med $\mathrm{J}$ 1969, 1: 531-536.

5. Seidl, L.G., Thornton, G.F., Smith, J.W. \& Cluff, L.E. Studies on the epidemiology of adverse drug reactions. III. Reactions in patients on a general medical service. Bull Johns Hopkins Hospital 1966, 119: 299-315.

6. Ewy, G.A., Marcus, F.I. \& Kapadia, G. Digoxin metabolism in the elderly. Clin Res 1968, 16: 27.

7. Dall, J.L.C. Digitalis intoxication in elderly patients. Lancet 1965, i: 194-195.

8. Herrmann, G.R. Digitoxicity in the aged. Recognition, frequency and management. Geriatrics 1966, 21: 109-122.

9. Riccitelli, M.L. \& Hirschfeld, H. Digitalis allergy: a study of 1,720 skin tests on 430 patients. J. Am Geriatr Soc 1961, 9: 277-284.

10. Soffer, A. The changing clinical picture of digitalis intoxication. Arch Intern Med 1961, 107: 113-120.

11. Taylor, B.B., Kennedy, R.D. \& Caird, F.I. Digoxin studies in the elderly. Age and Ageing 1974, 3: 79-84. scribed along with a diuretic. Potassium loss frequently occurs in elderly patients with a thiazide diuretic $^{34}$ and since the toxicity of digoxin is inversely related to serum potassium levels, this could cause problems. In the present study, there were 76 potential clinically significant drug-drug interactions due to the combined use of digoxin with a diuretic.

It has been stated in an editorial in the Lancet ${ }^{35}$ that the principle 'once on digoxin, always on digoxin' is no longer good practice. The findings from the present study indicate that there is a need for a review of the effectiveness and toxicity of maintenance digoxin treatment in elderly people.

\section{Acknowledgements}

We would like to thank the Social Services departments and in particular the officers-in-charge of the residential homes for their help and cooperation. We are also very grateful to the general medical pracitioners who provided the data.

12. Gibson, I.I.J.M. \& O'Hare, M.M. Prescription of drugs for old people at home. Geront Clin 1968, 10: 271-280.

13. Priddle, W.W. \& Rose, M. Curtailing therapy in a home for the aged, with special reference to digitalis, diuretics and low sodium diet. J Am Geriatr Soc 1966, 14: 731-734.

14. Fonrose, H.A., Ahlbaum, N., Bugatch, E., Cohen, M., Genovese, C. \& Kelly, J. The efficacy of digitalis withdrawal in an institutional aged population. $J$ Am Geriatr Soc 1974, 22: 208-211.

15. Hull, S.M. \& Mackintosh, A. Discontinuation of maintenance digoxin therapy in general practice. Lancet 1977, ii: 1054-1055.

16. Dall, J.L.C. Maintenance digoxin in elderly patients. Br Med J 1970, 2: 705-706.

17. Roberts, M.A. \& Caird, F.I. Steady-state kinetics of digoxin in the elderly. Age and Ageing 1976, 5: 214 223.

18. Whiting, B., Wandless, I., Sumner, D.J. \& Goldberg, A. Computer-assisted review of digoxin therapy in the elderly. Br Heart $J$ 1978, 40: 8-13.

19. Morgan, K., Gilleard, C.J. \& Reive, A. Hypnotic usage in residential homes for the elderly: a prevalence and longitudinal analysis. Age and Ageing 1982, 11: 229-234.

20. Bruce, S.A. Regular prescribing in a residential home for elderly women. Br Med J 1982, 284: 1235-1237.

21. Burns, C. Geriatric care in a Welfare home. Ulster Med J 1972, 41: 149-154.

22. Clarke, M.G., Williams, A.J. \& Jones, P.A. A 
psychogeriatric survey of old people's homes. $\mathrm{Br}$ Med $J$ 1981, 283: 1307-1310.

23. Knox, J.D.E. \& Melvin, M. Prescribed medicines in a residential home for the elderly. Nursing Times 1980, 76: $1934-1936$.

24. SPSS, SPSS-X User's Guide. McGraw-Hill, New York, 1983.

25. Siegal, S. Non-parametric Statistics for the Behavioural Sciences. McGraw-Hill International Book Company, London, 1956.

26. Shinn, A.F., Shrewsbury, R.P. EDI ${ }_{3}$. Evaluations of drug interactions 3. CV Mosby Co., St Louis, Mo, 1985.

27. Allwood, M.C., Free, K.H., Taylor, J.W. \& Wood, N.L. Survey of prescriptions dispensed for the elderly in East Anglia. Pharm J 1982, 229: 337.

28. Vener, A.M., Krupa, L.R. \& Climo, J.J. Drug usage and health characteristics in noninstitutional retired persons. J Am Geriatr Soc 1979, 27: 83-90.
29. Lemberg, L. Digitalis in congestive heart failure. Fact or fancy. Arch Intern Med 1978, 138: 451-452.

30. Johnston, G.D. \& Macdevitt, D.G. Is maintenance digoxin necessary in patients with sinus rhythm? Lancet 1979, i: 567-570.

31. Ewy, G.A., Kapadia, G.G., Yao, L., Lullin, M. \& Marcus, F.I. Digoxin metabolism in the elderly. Circulation 1969, 39: 449-453.

32. Cusack, B., Morgan, J., Kelly, J.G. et al. Pharmacokinetics of digoxin in the elderly. Proc $\mathrm{Br}$ Pharm Soc 1978, 15: 439-440.

33. B.N.F. British National Formulary No. 101985. British Medical Association and Pharmaceutical Society of Great Britain.

34. Schwartz, A.B., Diuretics in the treatment of hypertension. Drug Ther 1977, 7: 148-161.

35. Editorial. Needless digoxin. Lancet 1985, ii: 1048. 